\title{
UV polimerization of room temperature ionic liquids for high temperature PEMs: study of ionic moieties and crosslinking effects
}

\author{
J.Lemus $^{1}$, A. Eguizábal ${ }^{2}$, M.P. Pina ${ }^{2, *}$ \\ ${ }^{1}$ Centro Nacional de Energías Renovables-Fundación CENER-CIEMAT; Ciudad de la \\ Innovación, 31621 Sarriguren (Navarra), Spain \\ ${ }^{2}$ Nanoscience Institute of Aragón (INA); Edif. I+D, Campus Rio Ebro, c/Mariano \\ Esquillor s/n, 50018 Zaragoza, Spain \\ e-mail: mapina@unizar.es
}

\begin{abstract}
The conductivity performance of commercial available room-temperature ionic liquids (RTILs) has been evaluated from room conditions up to $200^{\circ} \mathrm{C}$ as a function of relative humidity for their potential application in high temperature PEMs. In particular, ammonium and imidazolium based ionic liquids with different counterions and substituents have been investigated. On the basis of conductivity performance, the best RTILs have been selected for the preparation of all solid state ion conductive films by bulk photo-assisted radical polymerization. The goodness of the UV photopolymerization of the respective monomeric ionic liquids (MILs) with vinyl functionality as a function of divynilbenzene cross-linker content has been evaluated by TGA and FTIR analyses. Poly-ionic liquid (PIL) films have been successfully accomplished for $\quad$ polymerized $\quad$ H-3-vinylimidazolium bis(trifluoromethanesulfonyl)imide upon exposure to $365 \mathrm{~nm}$ UV lamp with an intensity of $2.4 \mathrm{~mW} / \mathrm{cm}^{2}$ for $15 \mathrm{~min}$. Conductivity values above $1.1 \mathrm{~S} \cdot \mathrm{cm}^{-1}$ at $200^{\circ} \mathrm{C}$ have been registered for pure poly[1-(3H-imidazolium)ethylene bis(trifluoromethanesulfonyl)imide.
\end{abstract}




\section{Keywords:}

Ionic liquids moieties, vinyl polymerizable groups, ultraviolet induced polymerization, crosslinking, HT PEMs. 


\section{Introduction}

The use of room-temperature ionic liquids (RTILs) and polymeric ionic liquids (PILs) as electrolytes for high temperature fuel cell has been reported by several authors [1-3]; but still remains in its early stages [4-8]. RTILs exhibit two widely accepted generic properties: the melting point near or below room conditions and the ionicity higher than $99 \%$. Accounting from the huge diversity of cation-anion combinations, they are recognized as multipurpose materials on the basis on their tunable physico chemical properties (thermal and chemical stability, volatility, conductivity, polarity, melting point, viscosity, density etc.). Although a large number of different RTILs have been reported in the literature [9-10], imidazolium and ammonium based ones stand out as the most commonly used due to their straightforward synthesis and their commercial availability. Accordingly, they have been the selected families for this work. On the other hand, fluorinated anions have been described as the responsible for water-stability and high fluidity behavior [11-12], due to the weak van der Waals interaction between the $\mathrm{F}$ atoms and their neighboring cations.

ILs can act as proton solvents or transfer protons due to the presence of proton donor and acceptor sites [13]. Thus, a protic RTIL could replace acids (i.e., phosphoric acid) for HT PEMFC. In addition, the absence of volatility is one of the most important benefits of ILs. Thus, ILs could become the perfect candidates for the substitution of water dependent polymers. Considering this practical application, the main properties to take into account in the selection of ILs are thermal stability and, particularly, ionic conductivity. Nevertheless, one of the biggest requirements is the preparation of films having similar characteristics to ILs. Many publications deal with supported ionic liquid membranes for gas and liquid separation processes $[14,15]$. Our previous works [1618] describe the incorporation and testing of protic ionic liquids in micro-meso- 
macroporous materials for high temperature proton exchange membrane fuel cell (PEMFC) applications. The final aim is the replacement of typical proton carriers in PMFCs, i.e. mineral acids and water molecules, by RTILs. Our preliminary MEA tests [16] revealed $\mathrm{H}_{2} / \mathrm{O}_{2}$ single cell performances of $5.3 \mathrm{~mW} \mathrm{~cm}$ at $180^{\circ} \mathrm{C}$ under non humidified conditions for nanostructured membranes based on ETS-10 microporous titanosilicate (as diffusional barrier), and $\left[\mathrm{HMIm}^{+}\right]\left[\mathrm{TFSI}^{-}\right]$protic ionic liquid embedded on acid doped porous PBI (as electrolyte membrane). Similarly, van de Ven and cols [19] reported power density values of $0.039 \mathrm{~mW} \cdot \mathrm{cm}^{-2}$ at $150^{\circ} \mathrm{C}$ for tailor-made porous PBI support impregnated with $\left[\mathrm{HMIm}^{+}\right]\left[\mathrm{TFSI}^{-}\right]$as conductive filler. The impregnation of Nafion 112 with $\left[\mathrm{HSO}_{3}-\mathrm{BMIm}^{+}\right]\left[\mathrm{NTf}_{2}{ }^{-}\right]$ionic liquid rendered in peak power densities of $50 \mathrm{~mW} \cdot \mathrm{cm}^{-2}$ and $0.4 \mathrm{~mW} \cdot \mathrm{cm}^{-2}$ at $25^{\circ} \mathrm{C}$ under wet and dry conditions, respectively [8]. Among the published results on high temperature PEMFCs, the composite membrane based on polypropylene matrix impregnated with an ionic liquid tertiary amine phosphate $\left[\mathrm{N}_{111}{ }^{+}\right]\left[\mathrm{H}_{2} \mathrm{PO}_{4}^{-}\right]$is clearly outstanding [4]. Such RTIL liquid exhibited conductivity of $30 \mathrm{mS} \cdot \mathrm{cm}^{-1}$ at $160^{\circ} \mathrm{C}$ and provided to the composite membrane (loading as high as $1800 \%$ wt.) with maximum power density of $120 \mathrm{~mW} \cdot \mathrm{cm}^{-2}$ at $140^{\circ} \mathrm{C}$ under anhydrous conditions. Polymer gel electrolytes can be easily prepared by polymerization of monomers in presence of ionic liquids. As an example, Kiatkittikul and cols [20] prepared composite membranes by addition of $\left[\mathrm{EMPyr}^{+}\right]\left[(\mathrm{FH})_{1.7} \mathrm{~F}^{-}\right]$ionic liquid to the HEMA monomer in presence of radical initiator. The composite membranes exhibited ionic conductivity and maximum power density values of 81.9 $\mathrm{mS} \mathrm{cm}{ }^{-1}$ (at $120^{\circ} \mathrm{C}$ ) and $32 \mathrm{~mW} \mathrm{~cm}^{-2}$ (at $50^{\circ} \mathrm{C}$ ) respectively. It is worthwhile to mention the performance decay at temperatures above $50^{\circ} \mathrm{C}$ due to the softening of the composite HEMA based membrane. Thus, it can be concluded that some important 
issues related to the embedding, stabilization mechanisms and durability performance of protic ionic liquids under relevant conditions $[21,22]$ are still open.

An all solid state polymer electrolyte has advantages that include safety, stability and mechanical properties. Thus, the goal of this work is the preparation of ion conductive polymer films by polymerization of ionic liquid monomers. Ionic liquid-containing polymers by direct bulk polymerization of $\mathrm{N}$-vinyl imidazoliums were firstly reported by Ohno et al [23] in 1998. Unfortunately, the ionic conductivity was about 1000 times lower after radical polymerization (from $10 \mathrm{mS} \cdot \mathrm{cm}^{-1}$ to $10 \mu \mathrm{S} \cdot \mathrm{cm}^{-1}$ at $60^{\circ} \mathrm{C}$ for the EVIm $^{+}$TFSI $^{-}$system) mainly due to a reduced number of mobile ions. Since then, conventional free-radical polymerization technique [24-28] has been widely used for the preparation of polymerized ionic liquids from mainly styrene derivatives, acrylic/methacrylic ester derivatives, vinyl ethers. In most of the cases, the polymerization process is induced by thermal initiators and usually needs relatively high temperatures $\left(\sim 70-80^{\circ} \mathrm{C}\right)$ and long reaction times $(2-24 \mathrm{~h})$. Lately, free radical photopolymerisation (UV-curing) at room temperature has gained significant importance [8, 27, 29-35]. This technique is versatile, easy to use, fast (minutes or seconds) and environmentally friendly, as energy consumption is low and there is no emission of volatile organic compounds, as the use of solvent is almost avoided. Moreover, it enables the full control of the process because the polymerization starts when the light is switched on and stops when the light is cut off. More specifically, the photopolymerization of ammonium and imidazolium RTIL monomers with either acrylate [32-34] or styrene-based [8, 34-36] polymerizable groups have been already described for the preparation of dense films (20-200 $\mu \mathrm{m}$ in thickness) after $300 \mathrm{~s}$ of irradiation time. Recently, Ortiz and cols $[36,8]$ have reported the conductivity and fuel 
cell performance of polymerized imidazolium-based protic ionic liquid $\left[\mathrm{HSO}_{3}-\right.$ BVIm $\left.^{+}\right]\left[\mathrm{OTf}^{-}\right]$achieving peak power density of $25 \mathrm{~mW} \cdot \mathrm{cm}^{-2}$ at $40^{\circ} \mathrm{C}$ under dry conditions. Accounting from these results, the aim of this work is the preparation of conductive polymer films by photopolymerization of ionic liquid monomers with enhanced conduction performance for high temperature PEMFCs applications (up to $\left.175^{\circ} \mathrm{C}\right)$. Firstly, the best RTILs for proton conduction are identified among those preliminary selected on the basis on cation and anion families, protic/aprotic character and aliphatic chain length. Then, a similar characterization is performed over the corresponding RTIL monomers with vinyl polymerizable groups. The second part of this work has been devoted to the UV homopolymerization and the study of divinylbenzene addition (up to 7.2 molar \%) as cross-linker. The success in the photopolymerization has been evaluated by means of FTIR and TGA analysis of the as prepared films. Finally, the conductivity values and mechanical properties of the only

successful poly(ionic liquid) family, poly[1-(3H-imidazolium)ethylene] bis(trifluoromethanesulfonyl)imide, has been measured as a function of the cross-linker and compared with published data for similar systems.

\section{Experimental methods}

\section{$2.1 \quad$ Materials}

The six selected RTILs, belonging to the imidazolium (RTIL1, RTIL3, RTIL4, RTIL5) and ammonium (RTIL2, RTIL6) families, were carefully chosen among a wide of commercial available options to investigate the effect of substituents (methyl-, ethyl-, hydroxy-) and counterions (bis(trifluoromethanesulfonyl)imide, phosphonate, sulfonate) on conductivity. Thus, protic (on the cation RTIL1, RTIL2, RTIL4; on the anion 
RTIL3, RTIL5) and aprotic (RTIL6) ionic liquids are under study. Table 1 shows the set of imidazolium and ammonium RTILs supplied by SOLVIONIC and used in this work.

Table 1. Selected RTILs in this work

\begin{tabular}{|c|c|c|}
\hline Abbreviation & RTIL name and purity & Chemical structure \\
\hline RTIL1 & $\begin{array}{l}\text { H-3-methylimidazolium } \\
\text { bis(trifluoromethanesulfonyl)imide } \\
99.5 \% \text { wt. }\end{array}$ & \\
\hline RTIL2 & $\begin{array}{c}\mathrm{N}, \mathrm{N} \text {-dimethyl-N-(2-hydroxyethyl)ammonium } \\
\text { bis(trifluoromethanesulfonyl)imide } \\
99.5 \% \mathrm{wt} \text {. }\end{array}$ & \\
\hline RTIL3 & $\begin{array}{l}\text { 1-ethyl-3-methylimidazolium ethyl- } \\
\text { phosphonate } \\
99.5 \% \text { wt. }\end{array}$ & \\
\hline RTIL4 & $\begin{array}{l}\text { H-3-methylimidazolium methanesulfonate } \\
\qquad 99.0 \% \mathrm{wt} .\end{array}$ & \\
\hline RTIL5 & $\begin{array}{c}\text { 1-ethyl-3-methylimidazolium } \\
\text { methylphosphonate } \\
98.0 \% \text { wt. }\end{array}$ & \\
\hline RTIL6 & $\begin{array}{c}\text { (2-Hydroxyethyl)trimethylammonium } \\
\text { dimethylphosphate } \\
99.0 \% \text { wt. }\end{array}$ & \\
\hline
\end{tabular}

The selected imidazolium and ammonium-type ionic liquid monomers, denoted as MILs for the remainder of this work, with vinyl polymerizable groups, also supplied by SOLVIONIC; for the photopolimerization reactions were the following: MIL1/1-H-3vinylimidazolium bis(trifluoromethanesulfonyl)imide $(98.0 \mathrm{wt} \%) ;$ MIL2/N, N- 
dimethylprop-1-one-2-enammonium bis(trifluoromethanesulfonyl)imide (99.0 wt \%); MIL3/1-ethyl-3-vinylimidazolium ethylphosphonate (99.0 wt \%). As photo-initiator 2hidroxy-2-methylpropiophenone (Aldrich, $97.0 \mathrm{wt} \%$ ) was used, and divinylbenzene (Aldrich, $80.0 \mathrm{wt} \%$ ) as inert styrene cross-linker.

2.2 Preparation of ion conductive polymer films by UV polymerization of ionic liquid monomers

Films of poly(ionic liquids) (PILs), 100-200 microns in thickness, pure or crosslinked with divinylbenzene were obtained upon UV irradiation of the corresponding MIL, photoinitiator and cross-linker mixtures. Firstly, $5 \mathrm{~g}$ of MIL were mixed with the matching amounts of cross-linker agent (from 1.4 to 7.2 molar \%) and 1 wt $\%$ of a photoinitiator (2-hydroxy-2-methylpropiophenone) under stirring at $50^{\circ} \mathrm{C}$. Casting of MIL solution was made on squared Teflon plates $(3 \mathrm{~cm} \times 3 \mathrm{~cm})$, previously heated at $50^{\circ} \mathrm{C}$. The plates were placed under a $365 \mathrm{~nm}$ UV lamp (Vilber Lourmat) with an intensity of $2.4 \mathrm{~mW} / \mathrm{cm}^{2}$ at the sample surface and exposed for 15 minutes. Afterwards, the plate was removed and the solid film was then carefully peeled from the Teflon surface by inserting a clean blade and kept in a dry place.

\subsection{Characterization techniques}

Conductivity performance of RTILs, MILs and PILs was studied by Electrochemical Impedance Spectroscopy (EIS) using an Agilent 4294A Precision Impedance Analyzer from $40 \mathrm{~Hz}$ to $110 \mathrm{MHz}$. Basically, through-plane conductivity measurements, under $100 \mathrm{~cm}^{3} \mathrm{~N}_{2} \mathrm{STP} / \mathrm{min}$ as sweep gas, has been evaluated up to $200^{\circ} \mathrm{C}$ in a closed homemade stainless-steel conductivity cell PTFE lined inside provided with gold electrodes. This design, fully described in our previous works [16, 18, 37], was adapted from the models established by Sumner [38]. Considering water is the unavoidable by-product of 
PEM fuel cell reaction, the conductivity tests for RTILs and MILs were performed under dry (by sweeping with $\mathrm{N}_{2}$ stream from certified high purity gas cylinder > $99.998 \%$ ) and saturated ( $100 \%$ relative humidity at $20^{\circ} \mathrm{C}$ by sweeping with $\mathrm{N}_{2}$ stream after passing through water saturator trains bubblers at controlled temperature) conditions, respectively. For solid PILs films, the sample was squeezed between two Au electrodes; while for RTILs and MILs a dip-type quartz conductivity cell for liquid electrolytes was constructed with Au electrodes [39].

Thermogravimetric analyses (TGA) from room temperature up to $900^{\circ} \mathrm{C}$ under $\mathrm{N}_{2}$ flow and using $1^{\circ} \mathrm{C} / \mathrm{min}$ as heating rate (Q5000 IR TA Instruments) have been carried out to quantify water uptake values and decomposition temperatures of RTILs, MILs and PILs based films.

ATR-FTIR analyses (VERTEX 70 equipment with microscope slide MKII Golden Gate ATR from 4000 to $600 \mathrm{~cm}^{-1}, 256$ scans and resolution of $0.05 \mathrm{~cm}^{-1}$ ) were performed to investigate the absorption peaks of the MILs and their evolution upon UV photopolymerization reaction.

Stress-strain curves were used to specify the mechanical behavior, i.e. elasticity, of PILs films as a function of the cross-linker content. These experiments were performed at room temperature and consisted of incremental stretch relaxation tests using two high precision drive Instron Microtesters 5548 and 5248 with a $5 \mathrm{~N}$ full scale load cell and minimal resolution of $0.001 \mathrm{~N}$. For these tests, films of 500 microns thick of respective PILs were prepared. 


\section{Results}

\subsection{Conductivity Performance of RTILs}

Conductivity data from room temperature to $175^{\circ} \mathrm{C}$ are collected in Figure 1.A and 1.B for samples equilibrated in dry (0\% R.H.) and saturated (100\% R.H.) conditions. To the best of our knowledge, this work presents for the first time conductivity data at temperatures above $120^{\circ} \mathrm{C}$ for the selected RTILs families as a function of relative humidity. Most of the published works [5, 10-12] specify ion conduction at temperatures from $-50^{\circ} \mathrm{C}$ (above their $\mathrm{Tg}$ values) up to $120^{\circ} \mathrm{C}$ in the best case; with some exceptions [4]. The measured values for RTIL1 in dry conditions are in good agreement with those reported in the literature [40] for 1-n-butyl-3-methylimidazolium bis(trifluoromethanesulfonyl)imide. In particular, the shown tendency correlates with the higher local viscosity of 1-n-butyl-3-methylimidazolium bis(trifluoromethanesulfonyl)imide (denoted as $\mathrm{BMIm}^{+} \mathrm{TFSI}^{-}$) compared to RTIL1 as long as conductivity is coupled with the ions mobility. Thus, 17 and $100 \mathrm{mS} \cdot \mathrm{cm}^{-1}$ are measured at $\quad 100^{\circ} \mathrm{C}$ for $\quad$ 1-n-butyl-3-methylimidazolium bis(trifluoromethanesulfonyl)imide [40] and RTIL1, respectively.

As it was expected, all the RTILs exhibited higher conductivity values under fully hydrated conditions in accordance with their hydrophilic properties. With the exception of RTIL6, the registered conductivity values are over $100 \mathrm{mS} \cdot \mathrm{cm}^{-1}$ at $120^{\circ} \mathrm{C}$ under nonhumidified conditions; in accordance with their protic nature, i.e. H-Bond donor either on cation or anion. This observation underlines the proton-hopping mechanism involved, for which the donor-acceptor proton network provided by the protic ionic liquids is clearly beneficial.

Within the family of ammonium based RTILs, the protic RTIL2 (TFSI') clearly outperforms the aprotic RTIL6 $\left(\mathrm{M}_{2} \mathrm{PO}_{3}^{-}\right)$counterpart. For the same TFSI ${ }^{-}$anion (i.e. 
RTIL1, RTIL2), the best conducting cation depends on the relative humidity conditions. Thus, RTIL1 $\left(\mathrm{MIm}^{+}\right)$is preferred over RTIL2 (HODMA $\left.{ }^{+}\right)$under dry conditions. On the contrary, RTIL2 is clearly outperforming at $100 \%$ R.H. due to hydrogen bonding over hydroxyl groups contribution.

Remarkable differences in conduction behavior are shown by RTIL4 as a function on the relative humidity. Under dry inert atmosphere, the conductivity values remain below $1 \mathrm{mS} \cdot \mathrm{cm}^{-1}$ for temperatures lower than $100^{\circ} \mathrm{C}$; with an onset temperature circa $120^{\circ} \mathrm{C}$. On the contrary, a monotonically increase in conductivity with temperature is observed in presence of humidity. This observation could be attributed to the viscosity decrease by the presence of water impurities dissolved in RTIL4. For the same protic MIm ${ }^{+}$ cation (i.e. RTIL1, RTIL4), the TFSI ${ }^{-}$anion is preferred (i.e. RTIL1) due to the higher amount of $\mathrm{H}$-bond acceptor sites for proton hopping.

For the same aprotic MEIm ${ }^{+}$cation and phosphonate anions (i.e. RTIL3, RTIL5), the larger alkyl substituent on the anion, i.e. RTIL3, undergoes better conduction properties. In fact, RTIL3 exhibits, among the tested, the best conduction performance values due to weak $\mathrm{H}$-bond donor of $\mathrm{P}-\mathrm{H}$ bond facilitating the proton-hopping. 


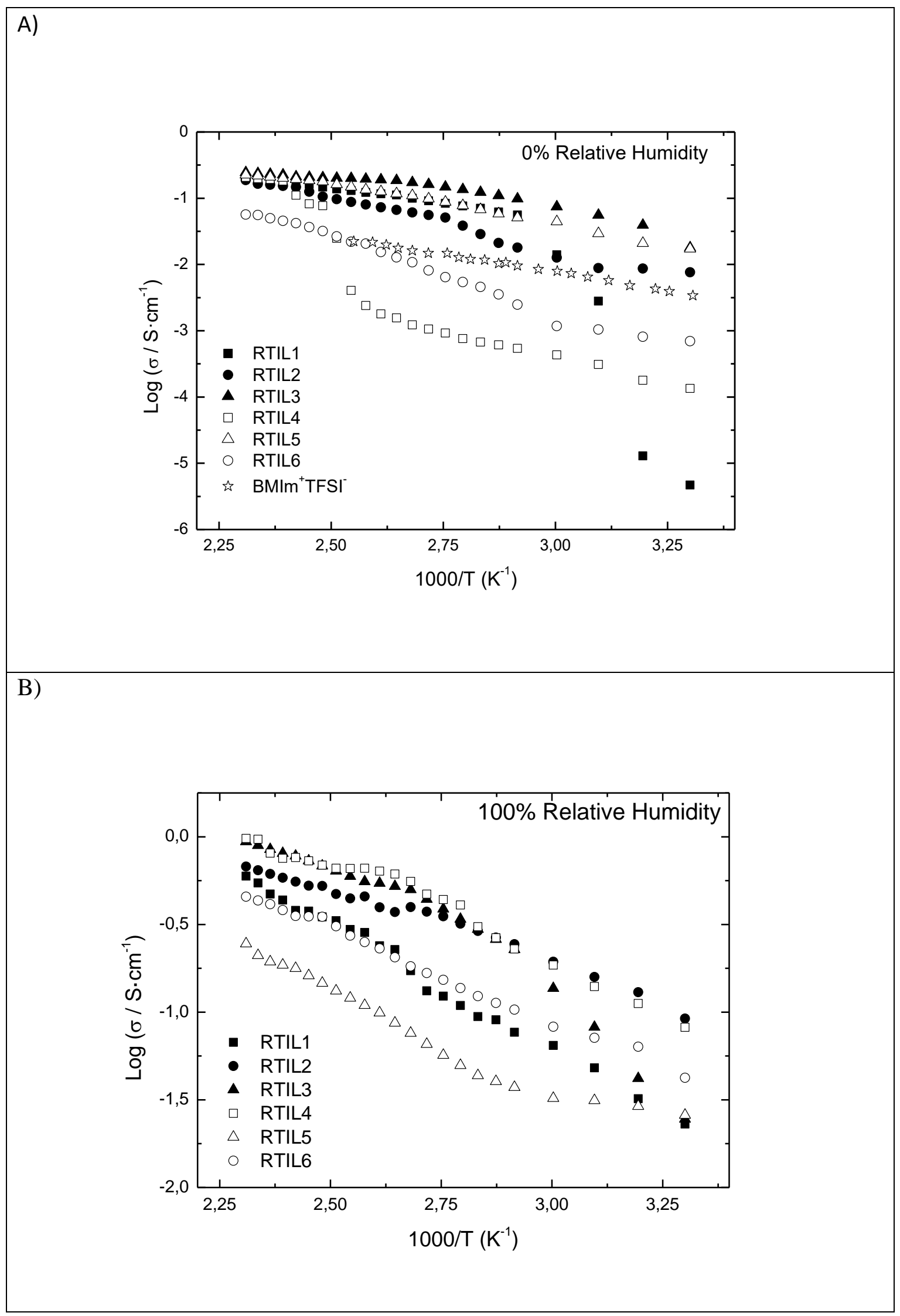

Figure 1. Arrhenius Plot of ion conductivity data of the selected RTILs for this study: A) dry conditions (BMIm ${ }^{+}$TFSI $^{-}$data adapted from Ref. 40); B) saturated conditions. 
Accordingly, RTIL1, RTIL2 and RTIL3 with $140,100,200 \mathrm{mS} \cdot \mathrm{cm}^{-1}$ at $120^{\circ} \mathrm{C}-0 \%$ R.H, and $295,500,560 \mathrm{mS} \cdot \mathrm{cm}^{-1}$ at $120^{\circ} \mathrm{C}-100 \%$ R.H, respectively; have been chosen for the preparation of ion conductive polymer films by photopolymerization of their corresponding MILs.

\subsection{Ion conductive polymer films by photopolymerization of ionic liquid monomers} with vinyl polymerizable groups

The Table 2 summarizes the three main families of protic ionic liquids selected in this work for the preparation of ion conductive films. Previous to the preparation of solid PIL films, the conductivity performance of the respective vinyl monomers (MILs), also commercially available, was investigated (see Figure 2). In general, under dry conditions MILs exhibit higher conductivity values than their respective RTILs, probably due to the stability and hydrogen bonding are favored on vinyl group versus methyl ones [41].

Table 2. Ionic Liquids studied in this work: from protic to monomer and polymer films.

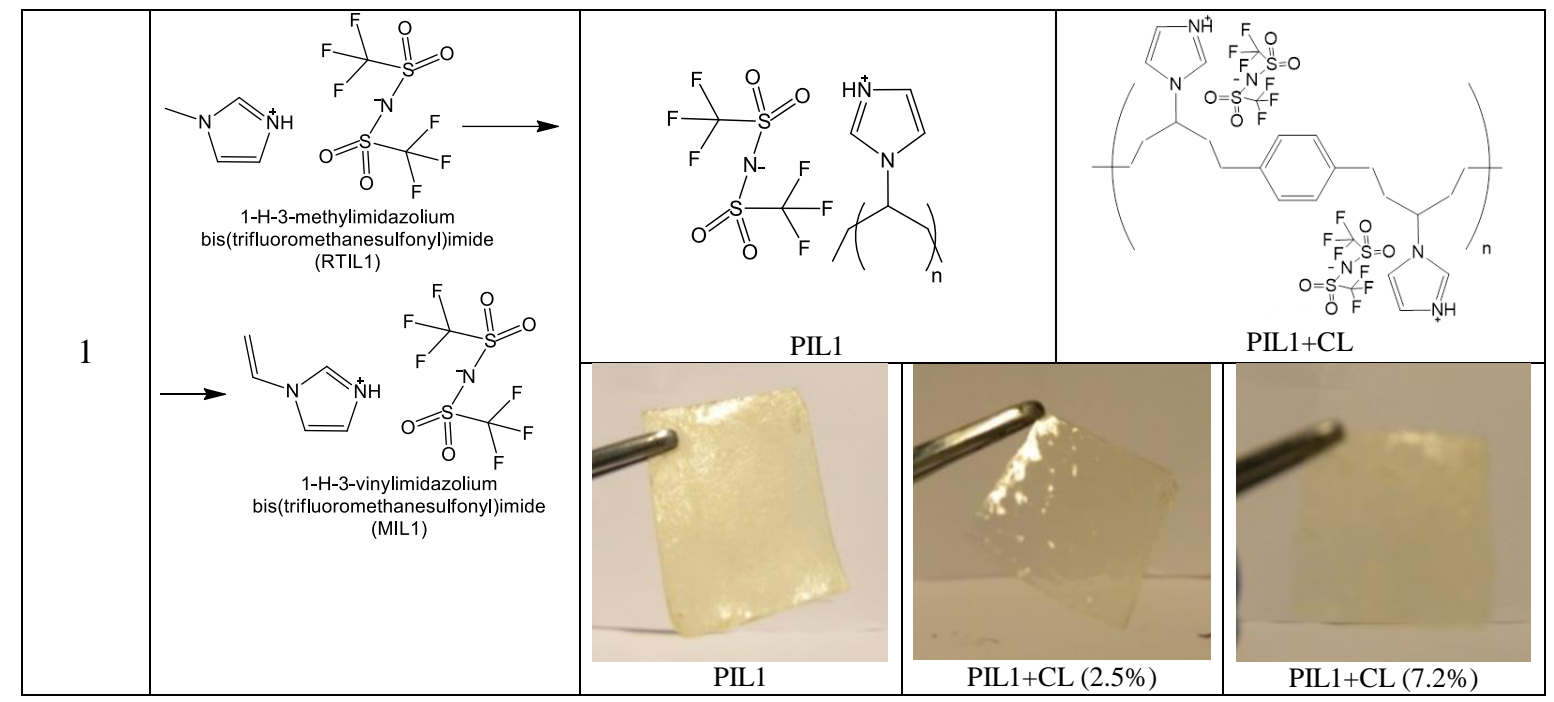




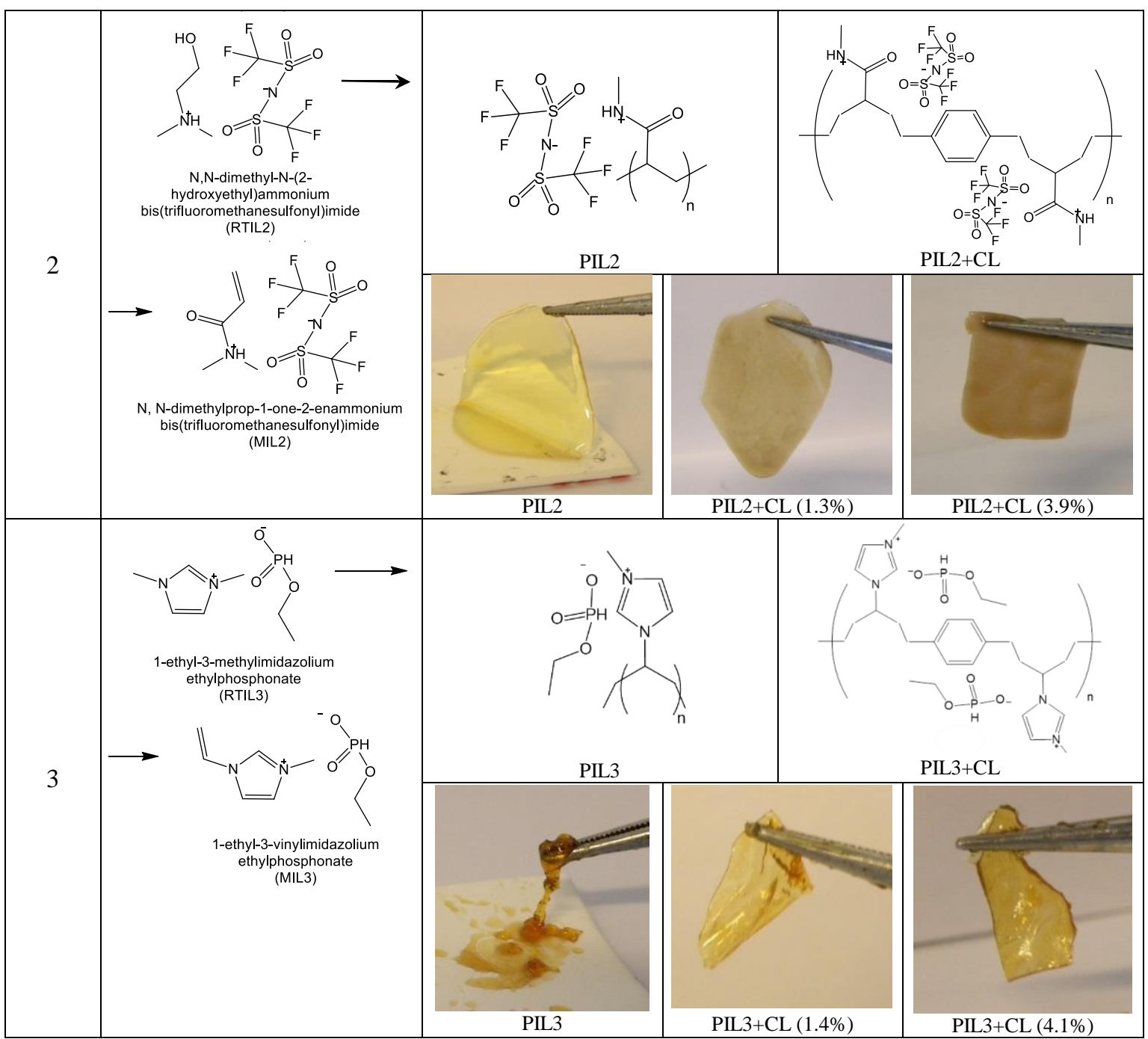

As it can be observed, the recorded conductivity values are always over $10 \mathrm{mS} \cdot \mathrm{cm}^{-1}$ at temperatures above $50^{\circ} \mathrm{C}$ whatever the relative humidity in the measuring chamber. In this temperature-operating window, the exhibited conductivity values for MIL1 are higher than those already reported $[10,23,24]$ for the similar 1-ethyl-3vinylimidazolium bis(trifluoromethanesulfonyl)imide (denoted as EVIm $^{+} \mathrm{TFSI}^{-}$) in agreement with the protic nature of MIL1. Thus, 8 and $74 \mathrm{mS} \cdot \mathrm{cm}^{-1}$ are measured at $60^{\circ} \mathrm{C}$ for $\mathrm{EVIm}^{+} \mathrm{TFSI}^{-}$and MIL1 respectively.

Similarly to RTILs, the conductivity on MILs is positively affected by the presence of water saturated $\mathrm{N}_{2}$ sweep gas. As an example, the conductivity values under dry conditions are $229-350-198 \mathrm{mS} \cdot \mathrm{cm}^{-1}$ and $306-485-269 \mathrm{mS} \cdot \mathrm{cm}^{-1}$ at $120^{\circ} \mathrm{C}$ and $160^{\circ} \mathrm{C}$ 
respectively for MIL1-MIL2-MIL3 data set. The analogous values at 100\% R.H are $351-1396-295 \mathrm{mS} \cdot \mathrm{cm}^{-1}$ and $426-1847-566 \mathrm{mS} \cdot \mathrm{cm}^{-1}$ at $120^{\circ} \mathrm{C}$ and $160^{\circ} \mathrm{C}$ respectively for MIL1-MIL2-MIL3 data set. Among the tested, the ammonium type derivative MIL1 seems clearly outperforming for ion transport.

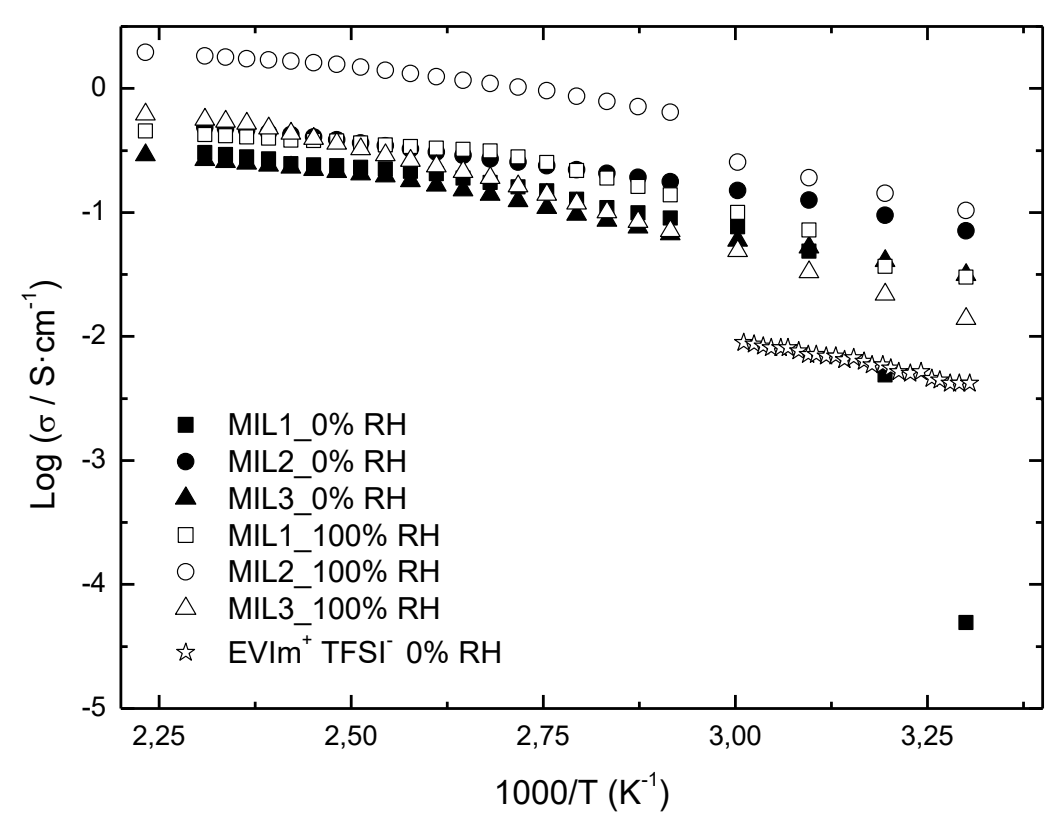

Figure 2. Arrhenius Plot of ion conductivity data for imidazolium and ammonium-type ionic liquid monomers of this study (EVIm ${ }^{+}$TFSI $^{-}$conductivity data adapted from [10]).

The expected poly-ionic liquids upon UV radiation of commercial MIL derivatives are the following: poly[1-(3H-imidazolium)ethylene] bis(trifluoromethanesulfonyl)imide (PIL1), poly[N,N-dimethylprop-1-one-2enammonium]bis(trifluoromethanesulfonyl)imide (PIL2) and poly[1-(3ethylimidazolium)ethylene] ethylphosphonate (PIL3).

Free radical polymerization of RTIL monomers is the most popular method to prepare PILs due to the great tolerance toward impurities, moistures, and other active 
and functional groups. It is well known that RTILs may contain hard-to-separate impurities from their synthesis by distillation (due to the negligible vapor pressure of RIILs). In our case, due to the hydrophilic character of MILs trace amount of moisture coexists. In fact, this is the reason for the light yellow appearance of the photopolymerized PIL2 and PIL3 samples (see pictures in Table 2); in spite of the absence of chromophores in their chemical structures. This observation agrees with the differential TGA analyses depicted in Figure 3 and summarized in Table 3 where the water sorption behavior is summarized for a proper comparison.
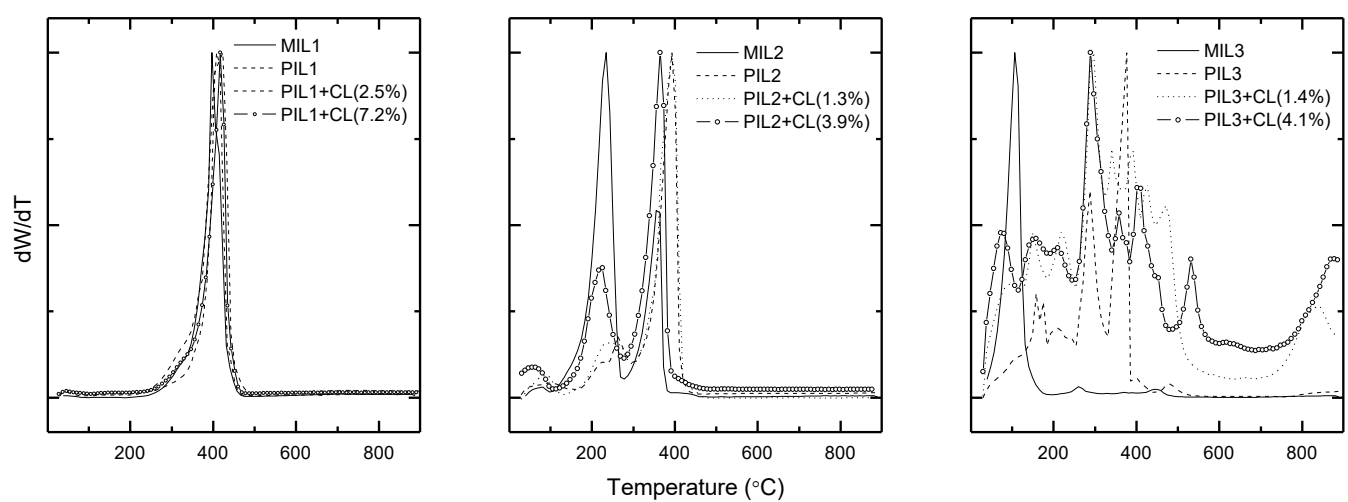

Figure 3. Differential TGA curves of the three families of PILs as a function of the crosslinker molar percentage, showing their varying thermal stabilities. The corresponding monomer derivatives are also depicted for comparison.

Table 3. Water sorption behavior of the selected RTILs, MILs and PILs for this work

\begin{tabular}{cccc}
\hline $\begin{array}{c}\text { Family } \\
\text { number }\end{array}$ & $\begin{array}{c}\text { Specimen } \\
\text { abbreviation }\end{array}$ & $\begin{array}{c}\text { Water uptake } \\
(\% \text { wt. })\end{array}$ & $\begin{array}{c}\mathrm{T}_{\max }^{(*)} \text { for water } \\
\text { desorption }\left({ }^{\circ} \mathrm{C}\right)\end{array}$ \\
\hline \multirow{4}{*}{1} & RTIL1 & 0.43 & 49 \\
& MIL1 & 0.34 & 49 \\
& PIL 1 & 0.78 & 48 \\
& PIL 1 + CL (2.5\%) & 0.65 & 48 \\
& PIL 1 + CL (7.2\%) & 0.55 & 48 \\
\hline \multirow{4}{*}{2} & RTIL2 & 22.75 & 87 \\
& MIL2 & 1.66 & 77 \\
& PIL 2 & 5.50 & 98 \\
& PIL 2 + CL (1.3\%) & 5.23 & 87 \\
& PIL 2 + CL (3.9\%) & 4.68 & 57 \\
\hline
\end{tabular}




\begin{tabular}{cccc} 
& RTIL3 & 20.85 & 104 \\
MIL3 & 18.90 & 109 \\
& PIL 3 & 16.91 & 106 \\
& PIL 3 + CL (1.4\%) & 10.96 & 95 \\
& PIL 3 + CL (4.1\%) & 10.34 & 77 \\
\hline
\end{tabular}

${ }^{(*)} \mathrm{T}_{\max }$ evaluated from the differential TG curves

In particular, RTIL2-MIL2-PIL2 and RTIL3-MIL3-PIL3 data set exhibit weight losses below $200^{\circ} \mathrm{C}$, attributable to water desorption. It is quite remarkable the exhibited water uptake values (below $0.8 \%$ wt) and the well-defined pattern of RTIL1-MIL1-PIL1 family, where only one decomposition peak at temperatures circa $410^{\circ} \mathrm{C}$ is clearly observed. On the contrary, several thermal events are identified on RTIL2-MIL2-PIL2 and RTIL2-MIL3-PIL3 thermograms. This behavior is clearly noticeable for MIL3PIL3, in agreement with the exhibited water uptake values, and reinforces our hypothesis on impurities coexistence and unsuccessful photopolymerization process. In all of cases, the water uptake values decrease with the divynilbenzene content due to the non-polar character of the cross-linker agent. For these reasons, the remainder of this work is devoted to the characterization of ion conductive polymer films based on the protic MIL1, i.e. 1-H-3-vinylimidazolium bis(trifluoromethanesulfonyl)imide as a function of the cross-linker addition.

3.3 Ion conductive polymer films from H-3-vinylimidazolium bis(trifluoromethanesulfonyl)imide: divinylbenzene crosslinking effects

The degrees of conversion of vinyl-polymerizable groups from MIL1/cross-linker mixtures $(0,2.5,7.2$ molar \%) to PIL1 based films were assessed using Fourier transform infrared (FTIR) analysis (see Figure 4). The characteristic infrared absorbance bands used to monitor the disappearance of the vinyl-monomer were 1662 
(stretching vibration in $\mathrm{C}=\mathrm{C}$ ) and $995 \mathrm{~cm}^{-1}$ (out of plane bending of the $-\mathrm{CH}=$ groups). Simultaneously, the asymmetrical stretching vibrations of the $-\mathrm{CH}_{2^{-}}$groups become more noticeable on PILs samples (2960-2850 $\left.\mathrm{cm}^{-1}\right)$.
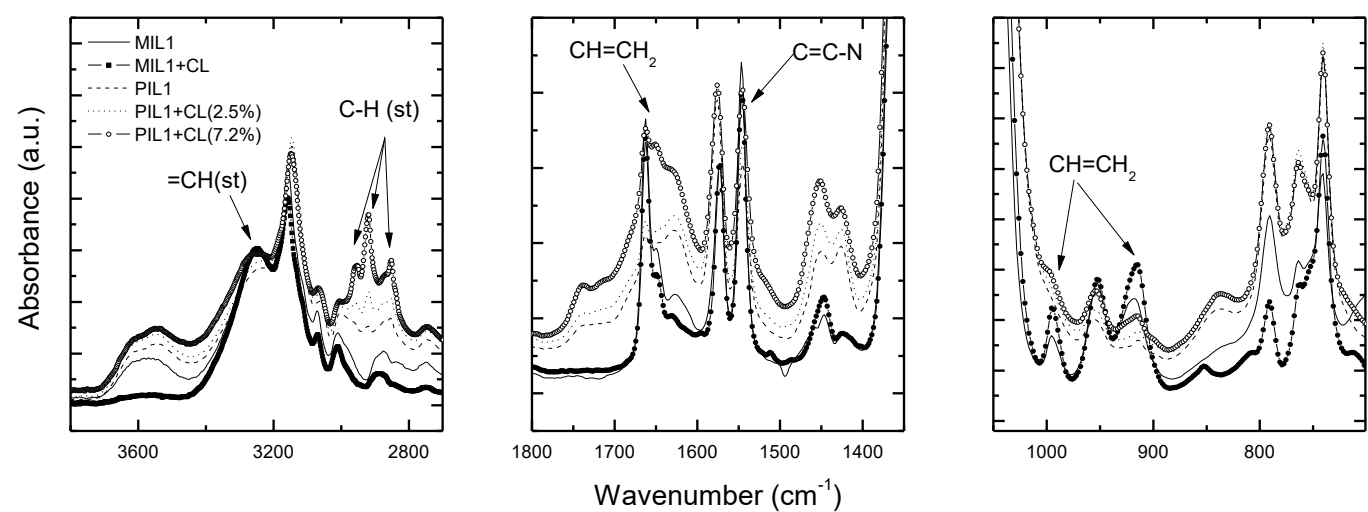

Figure 4. FTIR spectra of poly[1-(3H-imidazolium)ethylene] bis(trifluoromethanesulfonyl)imide (PIL1) samples as a function of the crosslinker molar percentaje. The starting 1-H-3-vinylimidazolium bis(trifluoromethanesulfonyl)imide monomer is included as reference.

As the final purpose of this work is the preparation of conductive polymer films for ion transport in absence of water, the conductivity performance for PILs was evaluated at dry conditions (see Figure 5). Unlike monomer derivatives, the protic PIL1 is clearly outperforming. At $60^{\circ} \mathrm{C}$, the exhibited conductivity value for PIL1 conduction value is very similar to the reported by Ohno et al. $[10,23,24]$ for polymerized [EVIm ${ }^{+} \mathrm{TFSI}^{-}$] as shown in Figure 5. Furthermore, the conduction performance shows an exponential growth at temperatures above $100^{\circ} \mathrm{C}$. Thus, the conductivity increases up to four orders of magnitude when temperature rises from $100^{\circ}$ to $125^{\circ} \mathrm{C}$. Very recently, Ortiz and cols [36] have studied the conductivity performance and mechanism of poly $\left[\mathrm{HSO}_{3}-\mathrm{BVIm}^{+}\right]\left[\mathrm{OTf}^{-}\right]$at temperatures near the glass transition values and up to $90^{\circ} \mathrm{C}$. These authors found a relationship between the water content of poly $\left[\mathrm{HSO}_{3}-\mathrm{BVIm}^{+}\right]\left[\mathrm{OTf}^{-}\right]$, the reduction in the glass transition temperature and the conductivity relaxation times. However, the herein studied PIL1 set emerges as the less hydrophilic family among the tested with water uptake values below $0.8 \%$ wt and 
maximum water desorption temperatures below $50^{\circ} \mathrm{C}$ (see Table 3). Therefore, the ability of our poly-ionic liquids to act as amphoteric materials for ion transfer through the hydrogen-bonded PIL network under anhydrous conditions is fully demonstrated.

Accounting from the above results, solid films from PIL1 seem quite attractive to be employed in high temperature PEMs. In fact, conductivity values of 1139, 371 and 98 $\mathrm{mS} \cdot \mathrm{cm}^{-1}$ have been achieved by PIL1, PIL+CL (2.5 molar \%) and PIL+ CL (7.2 molar $\%$ ) respectively at $200^{\circ} \mathrm{C}$. As it was expected, the conductivity drops with the $\%$ of cross-linker agent. On the other hand, the addition of divinylbenzene reveals quite effective to reinforce the mechanical properties of ion conductive PIL1 films. In this work, the Young's modulus values for PIL1 samples have been estimated from stressstrain curves performed at room temperature. This parameter describes the tendency of a material to be deformed elastically when a force is applied. In general, the lower the $\mathrm{E}$ modulus, the higher the flexibility of the specimen. As it was expected, the Young's modulus increases with the percentage of crosslinker: 215, 257, and $327 \mathrm{MPa}$ for PIL1, PIL+CL (2.5 molar\%) and PIL+ CL (7.2 molar \%) respectively. Similar elastic modulus, circa $200 \mathrm{MPa}$ has been reported for Nafion NR212 polymer electrolyte membrane at $90^{\circ} \mathrm{C}[42]$.

The Arrhenius plot of ion conductivity allows the estimation of the apparent activation energies for ion transport. The lowest value, i.e. $4.62 \mathrm{~kJ} / \mathrm{mol}$, corresponds to pure PIL1 due to the number of ion carriers and their mobility is the highest. For the PIL1+CL (2.5\%), the Ea is only slightly modified, $4.86 \mathrm{~kJ} / \mathrm{mol}$. Finally, the as calculated value for PIL1+CL (7.2\%) is $21.02 \mathrm{~kJ} / \mathrm{mol}$.

Considering the above results, it is concluded that conductive polymer films have been successful obtained from the bulky photopolymerization of MIL1in presence of 
2.5 molar\% of dyvinylbenzene as reinforcement agent. This formulation results as tradeoff between ion transport and mechanical properties.

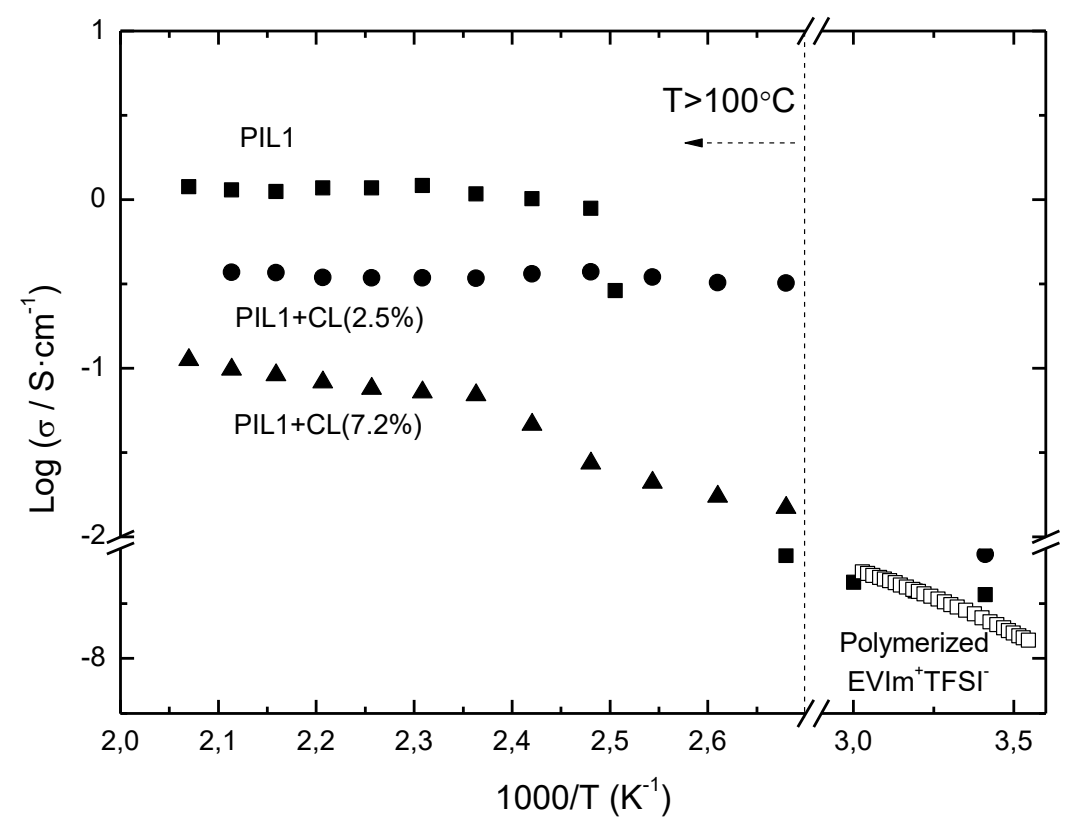

Figure 5. Arrhenius Plot of ion conductivity data for the poly[1- $(3 \mathrm{H}-$ imidazolium)ethylene] bis(trifluoromethanesulfonyl)imide (PIL1) samples as a function of the crosslinker molar percentaje (Polymerized MVIm $^{+}$TFSI $^{-}$conductivity data adapted from [10].

\section{Conclusions}

Among the selected RTILs for this study, RTIL3 exhibits the outperforming conduction behavior followed by RTIL1, and RTIL2. Under dry conditions, the registered ion conductivity values are quite acceptable for fuel cell applications (above $100 \mathrm{mS} / \mathrm{cm}$ for $\left.\mathrm{T}>120^{\circ} \mathrm{C}\right)$.

The photopolymerization of protic MILs with vinyl polymerizable functionalities upon exposure to UV irradiation $(365 \mathrm{~nm})$ for $15 \mathrm{~min}$ in presence of the photo initiator 2-hydroxy-2-methylpropiophenone has been successfully carried out for the MIL1 data set. The PIL1 films have demonstrated high potentialities as electrolyte membranes in 
high temperature PEMs. Among the tested, the PIL1 with 2.5 molar\% of divynilbenzene represents the optimal tradeoff between conductivity and mechanical properties. For this PIL film, the registered conductivity value at $200^{\circ} \mathrm{C}$ under dry conditions is $371 \mathrm{mS} / \mathrm{cm}$. Further studies with time on stream under real FC operating conditions to ensure their fully capabilities are in progress [43].

\section{Acknowledgements}

The authors would like to acknowledge financial support from the European Commission through the FP7 funded project ZEOCELL (http://ina.unizar.es/zeocell) Grant Agreement 209481.

\section{References}

1. Susan, M. A. B. H., Noda, A. Mitsushima, S. Watanabe, M. Bronsted acid-base ionic liquids and their use as new materials for anhydrous proton conductors. Chemical Communications, 2003(8): p. 938-939.

2. Fernicola, A., B. Scrosati, and H. Ohno. Potentialities of ionic liquids as new electrolyte media in advanced electrochemical devices. Ionics, 2006. 12(2): p. 95-102.

3. Fernicola, A.; Panero, S.; Scrosati, B.; Tamada, M.; Ohno, H. New Types of Brönsted Acid-Base Ionic Liquids-Based Membranes for Applications in PEMFCs. ChemPhysChem, 2007. 8(7): p. 1103-1107.

4. Ke, C., Li, J., Li, X., Shao, Z., and Yi, B. Protic ionic liquids: an alternative proton-conducting electrolyte for high temperature proton exchange membrane fuel cells. RSC Advances, 2012. 2(24): p. 8953-8956.

5. Díaz, M., A. Ortiz, and I. Ortiz. Progress in the use of ionic liquids as electrolyte membranes in fuel cells. Journal of Membrane Science, 2014. 469(0): p. 379396.

6. Liu, S., Zhou, L., Wang, P., Zhang, F., Yu, S., Shao, Z., and Yi, B. Ionic-LiquidBased Proton Conducting Membranes for Anhydrous H2/Cl2 Fuel-Cell Applications. ACS Applied Materials \& Interfaces, 2014. 6(5): p. 3195-3200.

7. Yuan, J., D. Mecerreyes, and M. Antonietti. Poly(ionic liquid)s: An update. Progress in Polymer Science, 2013. 38(7): p. 1009-1036.

8. Díaz, M., Ortiz, A., Vilas, M., Tojo, E. Ortiz, I. Performance of PEMFC with new polyvinyl-ionic liquids based membranes as electrolytes. International Journal of Hydrogen Energy, 2014. 39(8): p. 3970-3977.

9. Handy, S.T. Room Temperature Ionic Liquids: Different Classes and Physical Properties. Current Organic Chemistry, 2005.9 (10): p. 959-988.

10. Ohno, H. Functional Design of Ionic Liquids. Bulletin of the Chemical Society of Japan, 2006. 79(11): p. 1665-1680. 
11. Angell, C.A., N. Byrne, and J.-P. Belieres. Parallel Developments in Aprotic and Protic Ionic Liquids: Physical Chemistry and Applications. Accounts of Chemical Research, 2007. 40(11): p. 1228-1236.

12. Belieres, J.-P. and C.A. Angell. Protic Ionic Liquids: Preparation, Characterization, and Proton Free Energy Level Representation $\uparrow$. The Journal of Physical Chemistry B, 2007. 111(18): p. 4926-4937.

13. Lee, S.-Y., Ogawa, A., Kanno, M., Nakamoto, H., Yasuda, T., and Watanabe, M. Nonhumidified Intermediate Temperature Fuel Cells Using Protic Ionic Liquids. Journal of the American Chemical Society, 2010. 132(28): p. 97649773.

14. Liang, L., Q. Gan, and P. Nancarrow, Composite ionic liquid and polymer membranes for gas separation at elevated temperatures. Journal of Membrane Science, 2014. 450(0): p. 407-417.

15. Kárászová, M., Kacirková, M., Friess, K., and Izák, P. Progress in separation of gases by permeation and liquids by pervaporation using ionic liquids: A review. Separation and Purification Technology, 2014. 132(0): p. 93-101.

16. Eguizábal, A., J.Lemus, Roda, V., Urbiztondo, M., Barreras, F., and Pina, M. P. Nanostructured electrolyte membranes based on zeotypes, protic ionic liquids and porous PBI membranes: Preparation, characterization and MEA testing. International Journal of Hydrogen Energy, 2012. 37(8): p. 7221-7234.

17. Eguizábal, A., J. Lemus, and M.P. Pina. On the incorporation of protic ionic liquids imbibed in large pore zeolites to polybenzimidazole membranes for high temperature proton exchange membrane fuel cells. Journal of Power Sources, 2013. 222(0): p. 483-492.

18. Eguizábal, A. and M.P. Pina. Protic Ionic Liquids Confinement in Macro, Meso and Microporous Materials for Proton Conduction, in Encapsulation Nanotechnologies2013, John Wiley \& Sons, Inc. p. 347-389.

19. van de Ven, E., Chairuna, A., Merle, G., Benito, S. P., Borneman, Z., and Nijmeijer, K. Ionic liquid doped polybenzimidazole membranes for high temperature Proton Exchange Membrane fuel cell applications. Journal of Power Sources, 2013. 222(0): p. 202-209.

20. Kiatkittikul, P., T. Nohira, and R. Hagiwara. Nonhumidified fuel cell using Nethyl-N-methylpyrrolidinium fluorohydrogenate ionic liquid-polymer composite membranes. Journal of Power Sources, 2012. 220(0): p. 10-14.

21. Vangeli, O. C., Romanos, G. E., Beltsios, K. G., Fokas, D., Athanasekou, C. P., and Kanellopoulos, N. K. Development and characterization of chemically stabilized ionic liquid membranes-Part I: Nanoporous ceramic supports. Journal of Membrane Science, 2010. 365(1-2): p. 366-377.

22. Zhao, W., He, G., Nie, F., Zhang, L., Feng, H., and Liu, H. Membrane liquid loss mechanism of supported ionic liquid membrane for gas separation. Journal of Membrane Science, 2012. 411-412(0): p. 73-80.

23. Ohno, H. and K. Ito. Room-Temperature Molten Salt Polymers as a Matrix for Fast Ion Conduction. Chemistry Letters, 1998. 27(8): p. 751-752.

24. Ohno, H. Molten salt type polymer electrolytes. Electrochimica Acta, 2001. 46(10-11): p. 1407-1411.

25. Nishimura, N. and H. Ohno. 15th anniversary of polymerised ionic liquids. Polymer, 2014. 55(16): p. 3289-3297.

26. Chen, H. and Y.A. Elabd, Polymerized Ionic Liquids: Solution Properties and Electrospinning. Macromolecules, 2009. 42(9): p. 3368-3373. 
27. Yuan, J. and M. Antonietti. Poly(ionic liquid)s: Polymers expanding classical property profiles. Polymer, 2011. 52(7): p. 1469-1482.

28. Mecerreyes, D., Polymeric ionic liquids: Broadening the properties and applications of polyelectrolytes. Progress in Polymer Science, 2011. 36(12): p. 1629-1648.

29. Bongartz, N.A. and J.W. Goodby. Photopolymerization of self-organizing ionic liquids. Chemical Communications, 2010. 46(35): p. 6452-6454.

30. Gerbaldi, C., Nair, J. R., Ahmad, S., Meligrana, G., Bongiovanni, R., Bodoardo, S., and Penazzi, N. UV-cured polymer electrolytes encompassing hydrophobic room temperature ionic liquid for lithium batteries. Journal of Power Sources, 2010. 195(6): p. 1706-1713.

31. Ohno, H. and M. Yoshizawa. Preparation and Properties of Polymerized Ionic Liquids as Film Electrolytes, in Ionic Liquids IIIB: Fundamentals, Progress, Challenges, and Opportunities2005, American Chemical Society. p. 159-170.

32. Jiménez, Z., Bounds, C., Hoyle, C. E., Lowe, A. B., Zhou, H., and Pojman, J. A. Photopolymerization kinetics of ionic liquid monomers derived from the neutralization reaction between trialkylamines and acid-containing (meth)acrylates. Journal of Polymer Science Part A: Polymer Chemistry, 2007. 45(14): p. 3009-3021.

33. Zhou, H., Jiménez, Z., Pojman, J. A., Paley, M. S., and Hoyle, C. E. Photopolymerization kinetics of tributylmethylammonium-based (meth)acrylate ionic liquids and the effect of water. Journal of Polymer Science Part A: Polymer Chemistry, 2008. 46(11): p. 3766-3773.

34. Bara, J. E., Lessmann, S., Gabriel, C. J., Hatakeyama, E. S., Noble, R. D., and Gin, D. L. Synthesis and Performance of Polymerizable Room-Temperature Ionic Liquids as Gas Separation Membranes. Industrial \& Engineering Chemistry Research, 2007. 46(16): p. 5397-5404.

35. Simons, K., Nijmeijer, K., Bara, J. E., Noble, R. D., and Wessling, M. How do polymerized room-temperature ionic liquid membranes plasticize during high pressure CO2 permeation? Journal of Membrane Science, 2010. 360(1-2): p. 202-209.

36. Wojnarowska, Z., Knapik, J., Díaz, M., Ortiz, A., Ortiz, I., and Paluch, M. Conductivity Mechanism in Polymerized Imidazolium-Based Protic Ionic Liquid [HSO3-BVIm][OTf]: Dielectric Relaxation Studies. Macromolecules, 2014. 47(12): p. 4056-4065.

37. Sancho, T., J. Soler, and M.P. Pina. Conductivity in zeolite-polymer composite membranes for PEMFCs. Journal of Power Sources, 2007. 169(1): p. 92-97.

38. Sumner, M. J., Harrison, W. L., Weyers, R. M., Kim, Y. S., McGrath, J. E., Riffle, J. S., Brink, A., and Brink, M. H. Novel proton conducting sulfonated poly(arylene ether) copolymers containing aromatic nitriles. Journal of Membrane Science, 2004. 239(2): p. 199-211.

39. Eguizábal, A., J. Lemus, M. Urbiztondo, A.M. Moschovi, S. Ntais, J. Soler and M.P. Pina. Ammonium based ionic liquids immobilized in large pore zeolites: Encapsulation procedures and proton conduction performance. Journal of Power Sources, 2011. 196(9): p. 4314-4323.

40. Xu, W., E.I. Cooper, and C.A. Angell. Ionic Liquids: Ion Mobilities, Glass Temperatures, and Fragilities. The Journal of Physical Chemistry B, 2003. 107(25): p. 6170-6178.

41. Domagała, M. and S.J. Grabowski. Hydrocarbons as proton donors in C-H $\cdots \mathrm{N}$ and $\mathrm{C}-\mathrm{H} \cdots \mathrm{S}$ hydrogen bonds. Chemical Physics, 2010. 367(1): p. 1-6. 
42. Silberstein, M.N. and M.C. Boyce. Constitutive modeling of the rate, temperature, and hydration dependent deformation response of Nafion to monotonic and cyclic loading. Journal of Power Sources, 2010. 195(17): p. 5692-5706.

43. Lemus, J., A. Eguizábal, and M.P. Pina. Membranas reforzadas basadas en líquidos iónicos poliméricos para sus aplicación en procesos de transporte de iones y métodos de fabricación de dichas membranas. 2012. P201231812. 